\title{
Kuzey Kıbrıs Türk Cumhuriyeti'nde Hayvanlardan İzole Edilen Stafilokok Türlerinin Metisilin Dirençliliği Üzerine Retrospektif Bir Çalışma
}

\author{
Hüban Göçmen¹, Halit Şükürr1, Hazel Tamakan¹, Ömer Memduh Esendal ${ }^{1}$ \\ ${ }^{1}$ Yakın Doğu Üniversitesi, Veteriner Fakültesi, Mikrobiyoloji Anabilim Dalı, Lefkoşa, KKTC
}

Geliş Tarihi / Received: 02.10.2018, Kabul Tarihi / Accepted: 30.10.2018

\begin{abstract}
Özet: İnsanlarda ve hayvanlarda normal floranın bir parçası olarak kabul edilen stafilokokların bazı türleri, hayvanların ve insanların vücut bölgelerinde (örneğin; deri, kulak, eklem) çok çeşitli piyojenik infeksiyonlara neden olabilmektedir. Özellikle metisilin dirençliliği ile halk sağlı̆̆ açısından tehdit oluşturan stafilokok türlerinin başında Staphylococcus aureus gelmektedir. Bunu takiben $S$. pseudintermedius ve son zamanlarda da koagülaz negatif stafilokoklar say1labilmektedir.

Bu çalışmamızın amacı; Kuzey Kıbrıs Türk Cumhuriyeti'nde Yakın Doğu Üniversitesi Hayvan Hastanesine çeşitli şikayetlerle getirilen hayvanlardan izole edilen stafilokok türleri arasında metisilin dirençliliğini araştırmak ve zoonotik potansiyeli yüksek olan bu türlerin varlığını ortaya koymaktır. Hayvan hastanesine çeşitli şikayetlerle getirilen hayvanlardan 67 adet örnek toplanmış ve 80 adet stafilokok türü izole edilmiştir. Hayvanlara ait bu örneklerden koagülaz pozitif stafilokok türlerinden 22 adet $S$. aureus $(\% 27,5)$ ve koagülaz negatif stafilokok türlerinden ise 13 adet $S$. chromogenes $(\% 16,25)$ izole edilmiştir. Bu stafilokok türlerinin 22 adedi metisiline dirençli bulunmuştur. Klinik Laboratuvar Standartları Enstitüsüne (CLSI) göre yorumlanan mikrodilüsyon antibiyogram sonuçlarında çoklu antibiyotik dirençliliklerine de rastlanmıştır.
\end{abstract}

Anahtar Kelimeler: Evcil hayvanlar, Metisilin dirençliliği, Stafilokok türleri.

\section{A Retrospective Study about Methicillin Resistance of Staphylococcus Species Isolated from Animals at Turkish Republic of Northern Cyprus}

\begin{abstract}
Some species of staphylococci, considered to be part of the normal flora in humans and animals, can cause a wide variety of pyogenic infections in the body parts of animals and humans. In particular, main agent with regard to threatening public health is methicillin resistant S.aureus between Staphylococcus species then S.pseudintermedius and more recently, coagulase negative staphylococci can be counted.

The purpose of our study was investigate to methicillin resistance of Staphylococcus species isolated from the animals brought to animal hospital of Near East University in the Turkish Republic of Northern Cyprus and is demonstrate to presence of these species with high zoonotic potential. At animal hospital, 67 samples were collected from the animals which had various symptoms and 80 Staphylococcus species were isolated. The most isolated agents were 22 S.aureus (27,5\%) among coagulase-positive staphylococci and 13 S.chromogenes (16,25\%) among coagulase-negative staphylococci from the samples belonging to animals. It was obtained to methicillin-resistance at 22 of Staphylococcus species. Multiple drug resistance was also encountered in results of microdilution antibiotic susceptibility testing evaluated according to the Clinical Laboratory Standards Institute (CLSI).
\end{abstract}

Key words: Domestic animals, Methicillin resistance, Staphylococci.

\section{Giriş}

Stafilokoklar; fakültatif anaerob, Gram prozitif, katalaz pozitif, Micrococcaceae ailesinde bulunan bakterilerdir. Stafilokoklar; çeşitli memelilerde ve kuşlarda derinin ve müköz membraların ayrıca sindirim ve solunum yolunun normal bakteriyel florasının bir bölümünü oluşturmaktadır. Bunun yanında, stafilokokların bazı türleri hayvanların ve insanların vücut bölgelerinde (örneğin; deri, kulaklar ve eklemlerde) çok çeşitli piyojenik infeksiyonlara neden olabilmektedir [24,25].

Veteriner hekimliğinde; başlıca koagülaz pozitif stafilokok türlerinden S.aureus ve S.pseudintermedius ayrıca koagülaz negatif stafilokok türlerinden S.chromogenes ve S.epidermidis önemli hastaliklara neden olmaktadır. Koagülaz pozitif, oportunistik bir patojen olan Staphylococcus aureus; ineklerde, keçilerde, koyunlarda ve atlarda mastitise; koyunlarda ve keçilerde dermatitise; domuzlarda ve 
atlarda botriyomikozise ve kedi ve köpeklerde suppuratif infeksiyonlara neden olabilmektedir. S. hyicus ise domuzlarda eksudatif epidermitis ve artritis hastalığının etkenidir [25].

Koagülaz pozitif Staphylococcus intermedius grubunda (SIG); S. intermedius, S. pseudintermedius ve $S$. delphini türleri bulunmaktadır. Özellikle S. pseudintermedius, köpeklerde piyodermanın başlica etkenidir ve bu grubun üyeleri endometritis, sistitis ve otitis eksterna gibi suppuratif infeksiyonları meydana getirebilmektedir. Kedilerde de çeşitli piyojenik vakalara neden olmaktadır.

Koagülaz negatif stafilokoklar ise insanlarda ve hayvanlarda oportünistik infeksiyonlara yol açarken hayvanlarda en çok $S$. chromogenes, S. epidermidis, $S$. haemolyticus, $S$. simulans ve $S$. lugdunensis izole edilmektedir. İnsan sağlığında ise en çok S. hominis, $S$. capitis ve $S$. cohnii izole edilmektedir $[18,30]$.

Son zamanlarda metisilin dirençli stafilokokların artışı halk sağlığı açısından bir tehdit oluşturmaktadır. Bununla birlikte insanlarda ve hayvanlarda çoklu antibiyotik direncine sahip stafilokokların izole edilmesine dair birçok çalışma mevcuttur $[4,7,22]$. Özellikle metisilin dirençli Staphylococcus aureus (MRSA), metisilin dirençli Staphylococcus pseudintermedius (MRSP) ve metisilin dirençli koagülaz negatif Staphylococcus (MRCNS) türleri önemli infeksiyonlara yol açarken hayvanlar ve insanlar arasındaki taşıyıcılığı da önemli bir risk halini almıştır $[1,25,26]$.

Metisilin direnci, modifiye penisilin bağlayıcı protein (PBP2a) üretimini kodlayan mecA geni ile ilişkili bir durumdur. Genelde $\beta$-laktam antibiyotikleri bakteri hücre duvarı yapımını önlemek için, stafilokokların PBP'lerine bağlanır. Metisilin dirençli stafilokokların (MRS) modifiye olmuş PBP'i (PBP2a), $\beta$-laktamlar için düşük bir affiniteye sahiptir ve bu nedenle hücre duvarı yapımı bu antibiyotikler tarafindan engellenememektedir. $\mathrm{Bu}$ gen, 'stafilokokal kromozomal kaset' (SCCmec) olarak adland1rilan bir hareketli element üzerinde bakterinin kromozomunda bulunur [34].

Stafilokoklarda metisilin direncinin saptanması için fenotipik yöntemler kullanmaktadır. Genellikle metisilin yerine hassas ve daha dayanıklı oldukları için oksasilin veya sefoksitin antibiyotikleri yaygın olarak kullanılmaktadır. Metisilin dirençli sta- filokokların konvansiyonel antibiyotik duyarlılık testlerinin yanı sıra genotipik yöntemlerle özellikle PCR ile mecA geninin teşhisi, metisilin dirençli stafilokokların saptanması için altın standart olarak kabul edilmektedir [3,7,35].

$\mathrm{Bu}$ çalışmamızın amacı; Kuzey Kıbrıs Türk Cumhuriyeti'nde Yakın Doğu Üniversitesi Hayvan Hastanesine çeşitli şikayetlerle getirilen hayvanlardan izole edilen stafilokok türleri arasında metisilin dirençliliğini araştırmak ve zoonotik potansiyeli yüksek olan bu türlerin varlığını ortaya koymaktır.

\section{Materyal ve Metot}

\section{Hayvan Materyali}

$\mathrm{Bu}$ çalışmada; Yakın Doğu Üniversitesi Hayvan Hastanesine ve Yakın Doğu Üniversitesi Veteriner Fakültesi Uygulama Çiftliği'nden çeşitli şikayetler ile getirilen 34 adet köpek, 11 adet kedi, 10 adet at, 7 adet inek, 1 adet koyun, 2 adet keçi, 1 adet oğlak ve 1 adet kanaryadan oluşan toplamda 67 adet hayvana ait numuneler incelendi. Bu hayvan türlerine ait 29 adet deri svab1, 4 adet göz svab1, 8 adet süt örneği, 2 adet vaginal svap, 5 adet yara svab1, 9 adet kulak svabı, 2 adet deri kazıntısı, 1 adet irin içeriği, 2 adet idrar örneği, 1 adet piyoderma içeriği, 1 adet fistül svab1, 1 adet nazal svap ve 2 adet nekropsi materyali olmak üzere toplamda 67 adet numunenin bakteriyolojik izolasyon ve identifikasyonu yapıldı.

Numune alma kurallarına uygun olarak aseptik koşullarda MRSA (Copan-493CE03), likit Amies (Copan-4E014S.A) ve Stuart (Copan-141C) içeren svaplarla numuneler toplandi. Deri svaplar1; deri infeksiyonu bulunan bölgelere, steril ve bu amaca uygun seçilen svaplar sürülerek ve kulak svapları ise; otitis eksternalı hayvanların dış kulak yoluna sürülerek topland1. Süt örnekleri steril tüplere alınıp, ardından santrifüj edildi. İdrar örnekleri ise aynı şeklide aseptik bir ortamda sistosentez metodu ile topland. Toplanan numuneler Yakın Doğu Üniversitesi Veteriner Hekimliği Fakültesi Merkez Araştırma ve Mikrobiyoloji Laboratuvarına soğuk zincir altında ulaştırıldı ve bakteriyolojik analizlerine aynı gün başlandı.

\section{Bakteriyolojik İzolasyon ve İdentifikasyon}

Laboratuvara ulaştırılan örneklerin, \%7 koyun kanlı agara (Biomerieux, 43041), MacConkey aga- 
ra (Merck, 105465) ve koagülaz pozitif stafilokok türlerine spesifik olan Egg Yolk Tellurite (Merck, 103785.050) Supplement katılmış Baird Parker agara (Merck, 105406), MRSA agara (Himedia, M1974) ekimleri gerçekleştirildi. Pozitif kontrol olarak; Edinburg Üniversitesi Roslin Enstitüsü'nden Staphylococcus pseudintermedius ED99 ve Uludağ Üniversitesi Veteriner Fakültesi Mikrobiyoloji Anabilim Dalı'ndan tedarik edilen S. aureus ATCC 700699 suşları kullanılmıştır.

Ekimleri gerçekleştirilen besiyerleri, bakterilerin optimal üreme süreleri dikkate alınarak aerobik ortamda $37^{\circ} \mathrm{C}$ 'de inkübatörde inkübasyona birakıld1 ve izolasyonu gerçekleşen bakteri kolonileri değerlendirildi.

İzolasyonu gerçekleşen saf bakteri kolonilerine Gram boyama (Biomerieux,55542) yöntemi uyguland1 ve Gram özellikleri belirlendi. Gram pozitif kok şekilli mikroskobik morfoloji gösteren bakterilere katalaz (Biomerieux,55561) ve koagülaz (Merck,113306) testleri uyguland. VITEK 2 Compact (Biomerieux, France) otomatize sistem cihazı ve API Staph (Biomerieux, France) ile identifikasyonları gerçekleştirildi.

\section{Antibiyotik Duyarlılık Testi}

İdentifiye edilen stafilokok türlerinin metisilin dirençliliğini ortaya koymak amaciyla mikrodilüsyon yöntemi ile MIKK (minimal inhibitör konsantrasyon) değerleri tespit edildi ve Klinik Laboratuvar Standartlar1 Enstitüsüne (CLSI, M02-A12 ve M07-A10, 2017) göre yorumland1. İzolatlarda VITEK 2 Compact otomatize sistem cihazı ile AST-GP kartları kullanılarak mikrodilüsyon yöntemi ile toplamda 17 adet antibiyotiğe bakıldı ve duyarlılık/dirençlilik profilleri belirlendi. Metisilin dirençliliğinde rol oynayan Sefoksitin Tarama ve Oksasilin, AST kartlarında ayrıca belirtilmekte ve cihaz uyarı vermektedir.

\section{Bulgular}

Hayvan türleri, bu hayvanlara ait numune türleri, izole edilen stafilokok türleri ve bu türlerin metisilin dirençliliği ile ilgili bilgiler ve bulgular Tablo-1'de belirtilmiştir.

Tablo-1: Hayvan örneklerinden izole edilen stafilokok türleri ve metisilin dirençli stafilokok izolatları

\begin{tabular}{|c|c|c|c|}
\hline Numune Türü & \multicolumn{2}{|c|}{ Hayvan Türleri ve İzole Edilen Stafilokok Türleri } & $\begin{array}{l}\text { Metisilin Dirençli } \\
\text { Stafilokoklar }\end{array}$ \\
\hline \multirow{3}{*}{$\begin{array}{l}\text { Deri svab1 } \\
(\mathrm{n}=29)\end{array}$} & Köpek $(n=20)$ & $\begin{array}{l}\text { S. pseudintermedius }(\mathrm{n}=9), \operatorname{MRSP}(\mathrm{n}=1) \\
\text { S. epidermidis }(\mathrm{n}=1), \operatorname{MRCNS}(\mathrm{n}=1) \\
\text { S. } \text { aureus }(\mathrm{n}=1) \\
\text { S. intermedius }(\mathrm{n}=2), \operatorname{MRSI}(\mathrm{n}=2) \\
\text { S. chromogenes }(\mathrm{n}=3), \operatorname{MRCNS}(\mathrm{n}=3)\end{array}$ & \multirow{3}{*}{$\begin{array}{l}\operatorname{MRCNS}(n=12) \\
\operatorname{MRSA}(n=2) \\
\operatorname{MRSI}(n=2) \\
\operatorname{MRSP}(n=1)\end{array}$} \\
\hline & Kedi $(\mathrm{n}=1)$ & S.chromogenes $(\mathrm{n}=1)$ & \\
\hline & At $(n=8)$ & $\begin{array}{l}\text { S. aureus }(\mathrm{n}=3), \operatorname{MRSA}(\mathrm{n}=2) \\
\text { S. } \text { capitis }(\mathrm{n}=2), \operatorname{MRCNS}(\mathrm{n}=2) \\
\text { S. haemolyticus }(\mathrm{n}=1), \operatorname{MRCNS}(\mathrm{n}=1) \\
\text { S. } \text { chromogenes }(\mathrm{n}=4), \text { MRCNS }(\mathrm{n}=4) \\
\text { S. } \text { xylosus }(\mathrm{n}=1), \text { MRCNS }(\mathrm{n}=1) \\
\text { S. hyicus }(\mathrm{n}=1)\end{array}$ & \\
\hline \multirow{3}{*}{$\begin{array}{l}\text { Göz svabı } \\
(\mathrm{n}=4)\end{array}$} & Kedi $(n=2)$ & $\begin{array}{l}\text { Koagülaz Pozitif Staphylococcus spp. }(\mathrm{n}=1) \\
\text { S. chromogenes }(\mathrm{n}=1)\end{array}$ & \\
\hline & Köpek $(\mathrm{n}=1)$ & S. aureus $(\mathrm{n}=1)$ & \\
\hline & İnek $(\mathrm{n}=1)$ & Koagülaz Pozitif Staphylococcus spp. $(\mathrm{n}=1)$ & \\
\hline
\end{tabular}




\begin{tabular}{|c|c|c|c|}
\hline Numune Türü & \multicolumn{2}{|c|}{ Hayvan Türleri ve İzole Edilen Stafilokok Türleri } & $\begin{array}{l}\text { Metisilin Dirençli } \\
\text { Stafilokoklar }\end{array}$ \\
\hline \multirow[t]{3}{*}{ Süt $(n=8)$} & İnek $(\mathrm{n}=6)$ & $\begin{array}{l}\text { S. epidermidis }(\mathrm{n}=2), \text { MRCNS }(\mathrm{n}=1) \\
\text { Staphylococcus } \mathrm{spp} .(\mathrm{n}=1) \\
\text { S. aureus }(\mathrm{n}=1) \\
\text { S. chromogenes }(\mathrm{n}=2), \text { MRCNS }(\mathrm{n}=1) \\
\text { S. } \text { simulans }(\mathrm{n}=1) \\
\text { S. } \text { capitis }(\mathrm{n}=1), \text { MRCNS }(\mathrm{n}=1)\end{array}$ & \multirow[t]{3}{*}{$\begin{array}{l}\operatorname{MRCNS}(\mathrm{n}=3) \\
\operatorname{MRSA}(\mathrm{n}=1)\end{array}$} \\
\hline & Koyun $(\mathrm{n}=1)$ & S. aureus $(\mathrm{n}=1), \operatorname{MRSA}(\mathrm{n}=1)$ & \\
\hline & Keçi (n=1) & S. aureus $(\mathrm{n}=1)$ & \\
\hline \multirow{2}{*}{$\begin{array}{l}\text { Vaginal svap } \\
(\mathrm{n}=2)\end{array}$} & Köpek $(\mathrm{n}=1)$ & S. pseudintermedius $(\mathrm{n}=1)$ & \\
\hline & Keçi $(n=1)$ & S. aureus $(\mathrm{n}=1)$ & \\
\hline \multirow{2}{*}{$\begin{array}{l}\text { Yara svab1 } \\
(\mathrm{n}=5)\end{array}$} & Köpek (n=3) & $\begin{array}{l}\text { S. aureus }(\mathrm{n}=2) \\
\text { S. pseudintermedius }(\mathrm{n}=1)\end{array}$ & \\
\hline & Kedi $(n=2)$ & $\begin{array}{l}\text { S. aureus }(\mathrm{n}=2) \\
\text { S. caprae }(\mathrm{n}=1)\end{array}$ & \\
\hline \multirow{2}{*}{$\begin{array}{l}\text { Kulak svab1 } \\
(\mathrm{n}=9)\end{array}$} & Köpek (n=5) & $\begin{array}{l}\text { S. pseudintermedius }(\mathrm{n}=1) \\
\text { S. aureus }(\mathrm{n}=3) \\
\text { S. haemolyticus }(\mathrm{n}=1) \\
\text { S. simulans }(\mathrm{n}=1) \\
\text { S. } \text { capitis }(\mathrm{n}=1)\end{array}$ & \\
\hline & Kedi $(n=4)$ & $\begin{array}{l}\text { S. chromogenes }(\mathrm{n}=2) \\
\text { S. simulans }(\mathrm{n}=1) \\
\text { Koagülaz Pozitif Staphylococcus } \mathrm{spp} .(\mathrm{n}=2) \\
\text { Koagülaz Negatif Staphylococcus } \mathrm{spp} .(\mathrm{n}=1) \\
\text { S. aureus }(\mathrm{n}=1)\end{array}$ & \\
\hline $\begin{array}{l}\text { Deri kazıntıs1 } \\
(\mathrm{n}=2)\end{array}$ & At $(n=2)$ & $\begin{array}{l}\text { Staphylococcus } \text { spp. }(\mathrm{n}=1) \\
\text { S. capitis }(\mathrm{n}=1) \\
\text { S. hominis }(\mathrm{n}=1)\end{array}$ & \\
\hline $\begin{array}{l}\text { İrin içeriği } \\
(\mathrm{n}=1)\end{array}$ & Köpek $(\mathrm{n}=1)$ & S. aureus $(\mathrm{n}=1)$ & \\
\hline \multirow{2}{*}{$\begin{array}{l}\text { İdrar s1vis1 } \\
(\mathrm{n}=2)\end{array}$} & Kedi $(\mathrm{n}=1)$ & S. aureus $(\mathrm{n}=1)$ & \\
\hline & Köpek (n=1) & S. aureus $(\mathrm{n}=1)$ & \\
\hline $\begin{array}{l}\text { Piyoderma içerik } \\
(\mathrm{n}=1)\end{array}$ & Köpek (n=1) & S. aureus $(\mathrm{n}=1)$ & \\
\hline $\begin{array}{l}\text { Fistül svab1 } \\
(\mathrm{n}=1)\end{array}$ & Köpek $(\mathrm{n}=1)$ & S. aureus $(\mathrm{n}=1)$ & \\
\hline $\begin{array}{l}\text { Nazal svap } \\
(\mathrm{n}=1)\end{array}$ & Kedi $(n=1)$ & S. simulans $(\mathrm{n}=1)$, MRCNS $(\mathrm{n}=1)$ & MRCNS (n=1) \\
\hline \multirow{2}{*}{$\begin{array}{l}\text { Nekropsi materyali } \\
(\mathrm{n}=2)\end{array}$} & Kanarya $(\mathrm{n}=1)$ & S. auricularis $(\mathrm{n}=1)$ & \\
\hline & Oğlak $(\mathrm{n}=1)$ & S. xylosus $(\mathrm{n}=1)$ & \\
\hline $\begin{array}{l}\text { Toplam Numune } \\
\text { türü }=67\end{array}$ & $\begin{array}{l}\text { Toplam hayvan } \\
\text { türü }=67\end{array}$ & Toplam izolat sayısı $=80$ & $\begin{array}{l}\text { MRCNS }(\mathrm{n}=16) \\
\text { MRSA }(\mathrm{n}=3) \\
\text { MRSI }(\mathrm{n}=2) \\
\text { MRSP }(\mathrm{n}=1) \\
\text { Toplam Metisilin Dirençli } \\
\text { Stafilokok izolat sayıs }=22\end{array}$ \\
\hline
\end{tabular}




\section{Tartışma ve Sonuç}

Hayvanlarda metisilin dirençli S. aureus 1975 yılından itibaren bildirilmektedir [5]. Devriese ve ark. [5], 20 adet inekden toplanan süt örneklerinde 68 adet MRSA suşunun izole edildiği ve bu suşların tek bir insan kaynağından bulaştığını ileri sürmüşlerdir. İnsanlardan izole edilen $S$. aureus suşlarının çiftlik hayvanlarına taşınması, 1963 yılında Moeller ve ark.[19] tarafindan da bildirilmiştir. Aynı zamanda 47 adet koyundan toplanan süt örneklerinde yapılan bir çalışmada da \%29.8'inde mecA pozitif $S$. aureus izole edilmiştir [21]. Koyun ve keçi sütlerinde MRSA izolasyonu ve taşıyıcılı̆̆ 1 ile ilgili çalışmalar inek sütüne göre daha az sayıda rapor edilmiştir [2, $8,31]$, çalışmamızda ise çiftliklerden getirilen süt örneklerinde, koyun sütünden izole edilen 1 adet MRSA izolatı bulunmaktadır.

Diğer bir taraftan özellikle atlardan izole edilen ilk MRSA, Hartmann ve ark.[14] tarafindan postoperatif bir yaradan elde ettikleri bildirilmiştir. Bununla birlikte diğer bir çalışmada deri infeksiyonları bulunan atların 512 adet örneğinden 75 adet $S$. aureus izole edilmiş ve bunların ikisinde mecA geni taşıyıcılığı bulunarak MRSA olarak konfirme edilmiştir [3]. Atlardaki sporadik infeksiyonlara neden olan MRSA'ların insanlardan direkt olarak taşındığını ileri süren çalışmalar mevcuttur [28,29]. Laboratuvarımıza ulaştırılan 8 adet at deri svabından 3 adet $S$. aureus izole edilmiştir ve bunların 2 adedi MRSA olarak konfirme edilmiştir. Atlar veteriner fakültesi hayvan hastanesine getirilmeden, at çiftliğinde toplanan örnekler laboratuvara gönderilmiştir. Bu örneklerden izole edilen $S$. aureus suşlarının insanlar ve diğer hayvanlar için potansiyel bir kaynak olup olmadığıyla ilgili genotipik çalışmaların planlanması doğru bir yaklaşım olacaktır.

Aynı zamanda sağlıklı atlardan izole edilen koagülaz negatif Staphylococcus (CNS) türlerinde de mecA geni tespit edilmiş ve Japonya'da uygulanan bu çalışmada \%29,5 oranında mecA pozitif izolatlar elde edilmiştir [35]. Bizim çalışmamızda yukarıda bahsettiğimiz MRSA izolasyonu yapılan atların birinde, 2 adet MRCNS izolatı da bulunmuştur. $\mathrm{Bu}$ türler S. xylosus ve $S$. capitis olarak izole edilmiştir. Ayrıca atlardan izole ettiğimiz diğer MRCNS türleri S. chromogenes ve $S$. haemolyticus'dur. Bu sonucumuz ise Duijkeren ve ark.'nın [7] hayvan- larda metisilin dirençli Staphylococcus türlerinin araştırılması sırasında atlarda 4 adet mecA-pozitif S. haemolyticus suşunun elde etmesi ve bu suşların çoklu antibiyotik direnci bulunması ile uyumlu bulunmuştur. Çalışmamızdaki atlardan izole edilen $S$. haemolyticus suşunun oksasilin, sefoksitin, penisilin, ampisilin/sulbaktam ve sefaleksin'e karşı dirençli bulunurken; gentamisin ve klindamisin'e karşı duyarlı bulunmuştur.

Son yıllarda pek çok ülkede mastitise neden olan bakteriyel etkenler arasında koagülaz negatif stafilokokların (CNS) yer alması ve bakteriyel etkenlerin antibiyotiklere karşı gösterdikleri çoklu direnç sebebiyle sütçü işletmelerinde ekonomik kayıplara neden olduğu bildirilmiştir $[11,23,32]$. Hosseinzadeh ve Saei [15], İran'ın Doğu ve Batı Azerbaycan bölgelerinde bulunan yedi sütçü inek sürüsüne ait 158 süt örneğini bakteriyolojik ve moleküler (PCR-RFLP) yöntemlerle inceledikleri bir çalışmada $113(\% 71.5)$ örnekten birçok stafilokok türü izole etmişlerdir. 113 adet izolattan 5'ini (\% 4.4) $S$. aureus, 108'ini (\% 95.6) ise CNS olarak identifiye etmişlerdir. Araştırıcılar elde ettikleri $108 \mathrm{CNS}$ türünün 44'ünü (\% 40.7) S. haemolyticus, 17'sini (\% 15.7) S. chromogenes, 11 'er adedini (\% 10.2) S. epidermidis, S. arneri ve $S$. cohnii, 6'sin1 (\% 5.5) $S$. simulans, 4'ünü (\% 3.7) S. hominis, 3'ünü (\% 2.7) S. capitis ve 1'ini (\% 0.9) de S. xylosus olarak tanımlamışlardır. Klinik mastitis olgularından ise sadece $S$. haemolyticus, $S$. chromogenes ve $S$. warneri izole edilmiştir. Bizim çalışmamızda ise mastitis şikayetiyle laboratuvarımıza gelen toplamda 6 adet inek sütü örneğinden, 6's1 CNS olarak saptanırken, uygulanan antibiyogram testi sonucunda 3'ünde MRCNS tespit edilmiştir. Toplam izolat sayısına göre sütteki CNS oran1 \%7,5 iken; toplam metisilin dirençli stafilokok izolat sayısına göre MRCNS oran1 \%13,6 olarak bulunmuştur. Mastitis olgularında inek sütlerinden izole edilen MRCNS oranı \%13,6 iken, koyun keçi sütlerinde ise MRCNS izolasyonu gerçekleşmemiş ancak MRSA oran $1 \% 4,5$ olarak bulunmuştur.

2005 y1lında yeni bir stafilokok türü olan Staphylococcus pseudintermedius tanımlanmıştır [6]. Daha önce fenotipik özelliklerine göre $S$. intermedius olarak tanımlanan izolatlar daha sonra moleküler teknikler kullanılarak yeniden sınıflandırılmıştır [27]. S. pseudintermedius sağlıklı köpeklerin 
$\% 90$ 'ından izole edilebilir ve deri infeksiyonlarının (piyoderma, dermatitis vb.) altta yatan nedenlerinden biri olarak karşımıza çıkmaktadır $[9,13,26]$. Kawakami ve ark. [17], köpek piyodermasina neden olan en önemli patojenin S. pseudintermedius'un olduğunu ileri sürmüşlerdir [17]. Çin ve Japonya'da piyodermalı köpekler üzerine yapılan iki araştırmada MRSP prevalans1 sirasiyla \%48 ve \%66 olarak bulunmuştur [10,17]. Retrospektif çalışmamızda ise köpeklerin deri, yara, kulak ve vaginal svaplarından 12 adet $S$. pseudintermedius ve 2 adet $S$. intermedius izole edilmiş ve bunların 1 adedi MRSP ve 2 adedi MRSI olarak izole edilmiştir. MRSP infeksiyonlar1nın köpeklerde kedilere göre daha yaygın olduğunu içeren bildirimler mevcuttur [16,20]. Çalışmamızda bulunan kedilerden toplanan örneklerde de $S$. aureus ve ayrıca koagülaz pozitif stafilokoklar (CPS) izole edilmiştir ancak tiplendirilemeyen CPS'ler laboratuvarımızda sarfların azaldığı dönemlere denk gelmiş ve daha sonra tiplendirilmek üzere saklanmıştır. Kedilere ait $S$. aureus izolatlarımıza uygulanan mikrodilüsyon antibiyogram sonucunda metisilin dirençliliğine rastlanmamıştır.

Hollanda'da yapılan bir araştırmada, hayvanlarla temas1 olmayan insanlardan gelen burun svaplarının sadece \%4'ü MRSP pozitif iken, MRSP ile infekte köpekle teması olanların \%36'sı ve kediyle teması olanların \%31'i MRSP pozitif bulunmuştur [12]. Bu da, zoonotik öneme sahip bu mikroorganizmanın konakçısı olan kedi ve köpeklerin bulaşmadaki rolünü ortaya koymuştur ve uyguladığımız çalışmada metisilin dirençliliğinde ki artış araştırma konusu olarak ilgimizi çekmiştir.

Kuzey Kıbris Türk Cumhuriyeti'nde Yakın Doğu Üniversitesi Hayvan Hastanesine çeşitli şikayetlerle getirilen hayvanlardan 67 adet örnek toplanmış ve 80 adet stafilokok türü izole edilmiştir. Bu stafilokok türlerinin 22 adedi metisiline dirençli bulunmuştur. CLSI standartlarına göre yorumlanan antibiyogram sonuçlarında çoklu antibiyotik dirençliliklerine de rastlanmış ve bu yönde uygulanacak çalışmalara ihtiyaç duyulmuştur.

Sonuç olarak; hem insanların hem de hayvanların firsatçı patojeni olan stafilokok türlerinde, artan antibiyotik dirençliliklerinin ve bu türlerin taşınmasında rezervuar görevi gören hayvanların belirlenmesi her iki popülasyon içinde çok önemlidir. Antibiyotiklere direnç kazanmış bakterilerin neden olduğu infeksiyonlarda; duyarlı antibiyotik seçimi ve buna yönelik olarak doğru tedavi protokollerinin uygulanması aynı zamanda hastaların tedaviye cevap vermeleri, hastanede kalma süreleri ve tedavi giderlerinin azaltılmasına yönelik çalışmaların artması ülkemiz açısından önem arz etmektedir. Zoonotik karakterdeki MRSA gibi bakteriler için ciddi sağlık tedbirlerinin alınması ve taşıyıcılığı ile ilgili mücadele programlarının başlatılması gerekliliği tekrar ortaya çıkmıştır.

\section{Kaynaklar}

1. Beck KM, Waisglass SE, Dick H LN, Weese JS, (2012). Prevalence of meticillin-resistant Staphylococcus pseudintermedius (MRSP) from skin and carriage sites of dogs after treatment of their meticillin-resistant or meticillin-sensitive staphylococcal pyoderma. Vet Dermatol. 23, 369-375.

2. Bochev I, Russenova N, (2005). Resistance of Staphylococcus spp. strains isolated from goats with subclinical mastitis. Bulg J Vet Med. 8, 2, 109-118.

3. Chiers K, Decostere A, Devriese LA, Haesebrouck F, (2003). Bacteriological and mycological findings, and in vitro antibiotic sensitivity of pathogenic staphylococci in equine skin infections. Vet Rec. 138-40.

4. Davis JA, Jackson CR, Fedorka-Cray PJ, Barrett JB, Brousse JH, Gustafson J, Kucher M, (2014). Carriage of methicillin-resistant staphylococci by healthy companion animals in the US. Letters in Applied Microbiology. 59, 1-8.

5. Devriese LA, Hommez J, (1975). Epidemiology of methicillin-resistant Staphylococcus aureus in dairy herds. Res Vet Sci. 1, 23-7.

6. Devriese LA, Vancanneyt M, Baele M. et al, (2005). Staphylococcus pseudintermedius sp. nov., a coagulase-positive species from animals. Int J Syst Evol Microbiol. 55, 1569 73.

7. Duijkeren VE, Box A T A, Heck M E O C, Wannet W J B, Fluit A C, (2004). Methicillin-resistant staphylococci isolated from animals. Vet Microbiol. 103, 91-97.

8. El-Deeb W, Fayez M, Elmoslemany A, Kandeel M, Zidan K, (2018). Methicillin resistant Staphylococcus aureus among goat farms in Eastern province, Saudi Arabia: Prevalence and risk factors. Prev Med Vet. 156, 84-90.

9. Fazakerley J, Nuttall T, Sales D et al, (2009). Staphylococcal colonization of mucosal and lesional skin sites in atopic and healthy dogs. Vet Dermatol. 20, 179-184.

10. Feng Y, Tian W, Lin D, Luo Q, Zhou Y, Yang T, Deng Y, Liu Y H, Liu J H, (2012). Prevalence and characterization of methicillin-resistant Staphylococcus pseudintermedius in pets from South China. Vet Microbiol. 160, 517-24.

11. Gentilini E, Denamiel G, Betancor A, Rebuelto M, Rodriguez M, De Torrest RA, (2002). Antimicrobial susceptibility of coagulase negative staphylococci isolated from bovine mastitis in Argentina. J Dairy Sci. 85, 1913-1917. 
12. Guardabassi L, Loeber M, Jacobson A, (2004). Transmission of multiple antimicrobial-resistant Staphylococcus intermedius between dogs affected by deep pyoderma and their owners. Vet Microbiol. 98, 23-27.

13. Hanselman B A, Kruth S A, Rousseau J et al., (2009). Coagulase positive staphylococcal colonization of humans and their household pets. Can Vet J. 50, 954-958.

14. Hartmann FA, Trostle SS, Klohnen AA, (1997). Isolation of methicillin resistant Staphylococcus aureus from a postoperative wound infection in a horse. J Am Vet Med Assoc. 211, 1558-61.

15. Hosseinzadeh S, Saei HD, (2014). Staphylococcal species associated with bovine mastitis in the north west of Iran: Emerging of coagulase-negative staphylococci. Int J Vet Sci Med. 2, 27-34

16. Kadlec K, Schwarz S, Perreten V et al., (2010). Molecular analysis of methicillin-resistant Staphylococcus pseudintermedius of feline origin from different European countries and North America. J Antimicrob Chemother. 65, 1826-8.

17. Kawakami T, Shibata S, Murayama N, Nagata M, Nishifuji K, Iwasaki T, Fukata T, (2010). Antimicrobial susceptibility and methicillin resistance in Staphylococcus pseudintermedius and Staphylococcus schleiferi subsp. coagulans isolated from dogs with pyoderma in Japan. Journal of Veterinary Medical Science. 72, 1615-1619.

18. Lina G, Etienne J, Vandenesch F, (2000). Biology and pathogenicity of staphylococci other than Staphylococcus aureus and Staphylococcus epidermidis. pp: 450-462. In Fischetti VA, Novick RP, Ferretti JJ, Portnoy DA, Rood JI (EDS), Gram Positive Pathogens. ASM Press, Washington DC.

19. Moeller RW, Smith IM, Shemaker AC, Tjalma RA, (1963). Transfer of hospital staphylococci from man to farm animals. J Am Vet Med Assoc. 142, 613-7.

20. Morris DO, Rook KA, Shofer FS et al., (2006). Screening of Staphylococcus aureus, Staphylococcus intermedius, and Staphylococcus schleiferi isolates obtained from small companion animals for antimicrobial resistance: a retrospective review of 749 isolates (2003-04). Vet Dermatol. 17, 332-7.

21. Obaidat M, Bani Salman Alaa E, Roess Amira A, (2017). High prevalence and antimicrobial resistance of mecA Staphylococcus aureus in dairy cattle, sheep, and goat bulk tank milk in Jordan. Trop Anim Health Prod. 50, 2, 405412.

22. Pantosti A, (2012). Methicillin- resistant Staphylococcus aureus associated with animals and its relevance to human health. Frontiers in Microbiology. 3, 127.

23. Pitkälä A, Haveri M, Pyörälä S, Myllys V, Honkanen-Buzalski T, (2004). Bovine mastitis in Finland 2001-prevalence, distrubition of bacteria, and antimicrobial resistance. J Dairy Sci. 87, 2433- 2441.
24. Quinn PJ, Carter ME, Markey B, Carter GR, (1994). Staphylococcus species. In Clinical Veterinary Microbiology. Wolfe Publishing. 118-126.

25. Rich M, (2005). Staphylococci in animals: prevalence, identification and antimicrobial susceptibility, with an emphasis on methicillin-resistant Staphylococcus aureus. British Journal of Biomedical Science. 62,2, 98-105.

26. Sareyyüpoğlu B, Müştak HK, Cantekin Z, Diker KS, (2014). Methicillin Resistance in Staphylococcus pseudintermedius Isolated from Shelter Dogs in Turkey. Kafkas Universitesi Veteriner Fakültesi Dergisi. 20, 3, 435-438.

27. Sasaki T, Kikuchi K, Tanaka Y et al., (2007). Reclassification of phenotypically identified Staphylococcus intermedius strains. J Clin Microbiol. 45, 2770-8.

28. Seguin JC, Walker RD, Caron JP, Kloos WE, George CG, Hollis RJ, Jones RN, Pfaller MA, (1999). Methicillinresistant Staphylococcus aureus outbreak in a veterinary teaching hospital: potential humanto-animal transmission. J Clin Microbiol. 37, 1459-1463.

29. Shimizu A, Kawano J, Yamamoto C, Kakutani O, Anzai T, Kamada M, (1997). Genetic analysis of equine methicillinresistant Staphylococcus aureus by pulsed-field gel electrophoresis. J Vet Med Sci. 59, 935-937.

30. Shuttleworth RR, Behme RJ, McNabb A, Colby WD, (1997). Human isolates of Staphylococcus caprae: Association with bone and joint infections. J Clin Microbiol. 35, 2537-2541.

31. Spohr M, Rau J, Friedrich A, Klittich G, Fetsch A, Guerra B, Hammerl JA, Tenhagen BA (2011). Methicillin-resistant Staphylococcus aureus (MRSA) in three dairy herds in southwest Germany. Zoonoses Public Health. 58, 4, 25261.

32. Tenhagen BA, Koster G, Wallmann J, Heuwieser W, (2006). Prevalence of mastitis pathogens and their resistance against antimicrobial agents in dairy cows in Brandenburg, Germany. J Dairy Sc. 89, 2542-2551.

33. Virdis S, Scarano C, Cossu F, Spanu V, Spanu C, De Santis E P L, (2010). Antibiotic resistance in Staphylococcus aureus and coagulase negative staphylococci isolated from goats with subclinical mastitis. SAGE-Hindawi Accessto Research, Veterinary Medicine International.

34. Weese JS, Duijkeren E, (2010). Methicillin resistant Staphylococcus aureus and Staphylococcus pseudintermedius in veterinary medicine. Vet Microbiol. 140, 3-4, 418-429.

35. Yasuda R, Kawano J, Onda H, Takagi M, Shimizu A, Anzai T, (2000). Methicillin resistant coagulase negative staphylococci isolated from healthy horses in Japan. Am J Vet Res. 61, 1451-1455. 